\title{
Effect of Risk Management, Intellectual Capital on Performance of State Corporations in Kenya: Moderating Approach
}

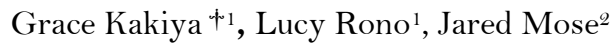 \\ ${ }^{1}$ Department of Accounting and Finance, Moi University, Kenya \\ ${ }^{2}$ Department of Economics and Agricultural Resource Management, Moi University, Kenya
}

\begin{tabular}{ll}
\hline ARTICLE INFO & ABSTRACT \\
\hline Article History & Purpose: \\
& The main aim of the study was to determine the moderating effect of intellectual capital on \\
Received $26 \quad$ November & the relationship between ERM risk structure practices and organizational performance of \\
$2019 ;$ & state corporations in Kenya. This study was guided by dynamic capabilities theory which \\
Accepted 16 March 2020 & attempts to explain the perspective of how intellectual capital and ERM practices affect \\
\hline JEL Classifications & organizational performance. \\
& Design/methodology/approach: \\
& The study used explanatory cross sectional survey design. Primary data on ERM risk \\
& structure practices, intellectual capital and organizational performance was collected from \\
& structured questionnaires. A survey was carried out on 218 state corporations in Kenya. The \\
& research hypothesis was tested using hierarchical regression analysis. \\
& Finding: \\
& The study found that intellectual capital had an enhancing and significant moderation effect \\
& on the relationship between ERM structure practice and organizational performance $(\beta$ \\
& $=.314, \rho<.05)$. \\
& Originality/value: \\
& This study contributes to theory by centering intellectual capital on the empirical testing of \\
& theory as well as the influence of intellectual assets on the relationship between enterprise \\
& risk management practices and organizational performance. In addition, the study supports \\
& the theory of Enterprise Risk Management (ERM) that emphasizes on holistic and \\
& company-wide approach of managing risks. The study further suggests that future research \\
& could build on this study by examining enterprise risk management practices in different \\
& sectors and industries using both financial and non-financial measures of performance.
\end{tabular}

Keywords:

Intellectual Capital, ERM

Structure Practices,

Organizational Performance

\begin{abstract}
1. Introduction
Firm performance indicators vary and largely depend on the core business of the organization and rationale for its existence. Thus organizations measure performance dissimilarly depending on the different sectors of the economy thus resulting to variations in performance. According to Hofer (2003) performance is a contextual concept linked to the occurrence being studied. Organizational performance has diverse definitions (Barney, 2002). Organizational performance encompasses actual production or results of an entity measured against its intended output for predetermined objectives and targets (Ongeti, 2014). Thus, determining the predictors of firm performance is paramount. Therefore, this study argues that enterprise risk management (ERM) is important in explaining performance of state corporations (SCs).

Bozkus (2014) opines that, while various companies have been engaging in some phases of ERM, studies show that only a few have a well-developed ERM infrastructure. Further, the study gave recommendations on the best practices to be applied when implementing a successful ERM framework based on practical issues and technical approaches

${ }^{\dagger}$ Corresponding Author: Grace Kakiya

Email: gkakiya@gmail.com
\end{abstract}


within the business environment. An effectual ERM model should have a structure that enables management to comprehend and communicate the organization's risk factors. A good risk management program in an organization is essential in handling operational challenges (Beasley et al., 2005). ERM structure practices within organizations' facilitate identification of uncertainties through a structure that aggregates the risk management events in a holistic framework (Hoyt and Liebenberg, 2011). ERM structure establishes the policies, processes, competencies, reporting, technology, and a set of standards for risk management. Pagach and Warr (2010) opine that the assessment of ERM structures enables firms to address all their risks, set common terminologies and expectations. That is, which risks the entity can take and which ones to avoid.

Thus, based on the above discussion the study presumed that firm performance is influenced by a host of ERM structure practices. However, the influence could be affected by intellectual capital. Therefore, survival of organizations in a dynamic environment can be ascribed to their use of intellectual assets. Intellectual capital (IC) is a group of knowledge assets that are ascribed to an organization and expressively contribute to improved competitive position by adding value to the defined key stakeholders (Marr et al., 2004). Organizations with higher intellectual capital are likely to withstand the effects of unanticipated changes in markets. Also, Sofian et al., (2014) opine that such organizations can effectively anticipate their risk exposure and handle them in a better way. Therefore, this study investigated the moderating role of intellectual capital on the relationship between ERM and organizational performance.

State corporations in Kenya are crucial for promoting and accelerating national growth and development through creation of employment opportunities as well as social economic transformation (Kenya National Bureau of Statitics (KNBS), 2015). However, the performance of SCs has been worrying over decades. KNBS, (2015) economic survey report indicated that firms in the private sector were reporting successes while SCs were reporting failures, missed opportunities and a few successes in the history of Kenya. As such, the Government through Treasury Circular number 3/2009 directed all chief executives of SCs to develop and implement institutional risk management framework as a strategic measure for managing risk. The directive was issued to ensure that organizations remain competitive and enhance their performance within the changing external environment. The adoption of risk management strategies in state-owned corporations in Kenya, aimed at incorporating and aligning SCs performance to Vision 2030. However, this has not achieved the projected traction (Republic of Kenya, 2013). This implies that SCs adopted ERM practices either as proactive (strategic) or reactive (compliance with regulations) measures. This study assessed the influence of ERM practices employed by SCs on organizational performance because SCs are of great interest to the government, general public and other stakeholders.

\section{Review of Literature}

\subsection{Theoretical Review}

This study was anchored on Dynamic Capabilities Theory which advances that organizational capabilities are the primary source of a firm's competitive advantage (Grant, 1991). Capability is the ability of an organization to perform a coordinated set of tasks, utilizing organizational resources, to achieve a particular goal (Helfat and Peteraf, 2003). Thus, application of dynamic capability perspective supports ERM in moving beyond an ex ante prediction of risky events, by providing managers with tools to recover from risky events that may occur. Therefore, dynamic capabilities thrusts beyond forecasting of risks to making organizations resilient to risks (Wohlgemuth and Bogodistov, 2017). Organizations develop risk-management capabilities for top tier management in order to sustain a competitive position in dynamic environment. Resilience in strategic risk management can be enriched by deliberately making investments in fundamental routines and processes which would result in dynamic managerial capabilities. For instance, Adner and Helfat (2003) suggest that managerial human capital can be construed to be part of dynamic managerial capabilities. Stewart (1997) posits that there are assets referred to as "invisible assets" which in real sense are intellectual capital. Therefore, intellectual capital encompasses resources and capabilities that are valuable, uncommon, poorly imitable and non-substitutable, which present a lasting competitive advantage and superior performance to the firm. Proponents of resource-based view and dynamic capabilities theory consider both ERM and intellectual capital as the prestigious resources of an organization. This research agrees with this view by proposing that the combined effect of ERM and intellectual capital can improve organizational performance.

\subsection{Previous studies}

Wood and Lewis (2018) evaluated the impact of risk culture development on Caribbean Development Bank. The study opines that risk culture is a balance between qualitative behavioral traits and quantitative control structures. Implying that, risk culture is an aggregate of the organization's strategy, processes, systems and people; articulated by how people think and behave in view of risk and its management. The study collected primary data through structured interview of Chief Risk Officer during the month of August 2015. Risk culture as part of ERM structure components was assessed using five attributes namely; policies and limits, strategies and goals, risk management structure, risk control processes, people and competence. It was observed that communication, awareness and accountability are strong indicators of Caribbean Development Bank's risk culture which contributed to improved uniformity of risk management knowledge, coordinated collation of risk data and better appreciation of risk management issues. Consequently, risk management practices were enhanced within Caribbean Development Bank.

Further, Olayinka et al., (2017) investigated the impact of ERM on financial performance of Nigerian financial sector. The study collected panel data from the annual reports obtained from individual company's website and 
Africanfinancials.com website. Data was obtained from 40 companies for the period between 2012 and 2016 . The study used Return on Assets (ROA) to measure financial performance while Value at Risk (VaR) was used as a proxy measure of ERM structure practices. VaR measures the organization's total risk component as a composite value; where a lower VaR implies that the organization is able to control its risk appetite thus a positive effect on financial performance while a higher VaR suggests negative influence on financial performance. Data was analyzed by use of fixed effect panel regression model while controlling for leverage, board size, firm size, institutional ownership and size of risk management committee. The study found that ERM structure practices had a positive a significant effect on financial performance on firms listed in the Nigerian financial sector.

Studies by Florio and Giulia (2016) investigated the relationship between the extent of implementation of ERM systems and performance of Italian listed companies. ERM systems were measured using proxies; appointment of a Chief Risk Officer, presence and reporting frequency of internal controls, and existence of risk committee. Further, ERM operating mechanism was assessed based on frequency, depth and methodology of risk assessment. Conversely, performance was measured using ROA and Tobin's Q. Secondary data was collected from non-financial companies listed on Milan Stock Exchange for the period 2011 to 2013 and analyzed using multivariate Ordinary Least Square regression models. The study found that firms with advanced levels of ERM implementation had higher performance, in respect to financial performance and market valuation. In addition, the study validated that effective ERM systems result to greater performance by way of reduced risk exposure.

ERM practices within the risk structure combine risk management events in a holistic framework to facilitate identification of uncertainties (Hoyt, \& Liebenberg, 2011). ERM structure establishes the policies, processes, competencies, reporting, technology, and a set of standards for risk management. Shad and Lai (2015) developed a conceptual framework for ERM performance measure through Economic Value Added. The framework hypothesizes that ERM structure practices have a significant impact on performance. Further, ERM structure practices need to be assessed using four indicators: (i) provision of a common understanding of the objectives of each ERM initiative (ii) provision of common terminology and set of standards of risk management (iii) identifying key risk indicators (KRIs) and (iv) integration of risk with key performance indicators (KPIs). The study was based on review of literature and recommends that empirical studies should be done to test the hypothesis. This study sought to test the hypothesis using similar risk structure practices measures developed by Shad and Lai (2015).

Bontis et al. (2000) investigated the elements of intellectual capital (human, structural and customer capital) and their inter-relationships within two industry sectors (service and non-service industries) in Malaysia. Primary data was collected using a psychometrically validated questionnaire developed by Bontis (1998). Data was analyzed using partial least squares because it was suitable for handling small data samples. The results of the study indicate that all the elements of intellectual capital (IC) have a positive and significant influence on business performance irrespective of the industry.

Bontis and Mention (2013) investigated the effects of IC on business performance in banks within Luxembourg and Belgium in May 2010. Primary data was collected using survey questionnaires developed by Bontis (1998) and modified by Cabrita and Bontis (2008). Intellectual capital was assessed in terms of human, structural and relational capital using the scorecard method. Data was analyzed by use of structural equation modeling. The study found that human capital contributes to business performance both directly and indirectly in the banking sector. In addition, structural and relational capital were positively associated to business performance. However, the effect was not statistically significant. The data collection instrument used was similar to that of Bontis et.al., (2000). However, variations in the results could be attributed to differences in the business environment.

Ting and Lean (2009), obtained data from the annual reports of 20 financial institutions listed in the finance sector of Bursa Malaysia for the period 1999 to 2007 to examine the association between IC and financial performance. Financial performance was measured using ROA while IC was measured using Value added intellectual coefficient (VAIC). Data was analyzed using linear multiple regression analysis. The results of this study indicated that there is a significant positive relationship between VAIC and ROA.

On the contrary, Mondal and Ghosh (2012) investigated the relationship between IC and financial performance of 65 Indian banks during the period 1999 to 2008. The study applied similar methodology like Ting and Lean (2009) to an Indian context by measuring IC using VAIC and analyzing data using multiple regression models. In addition, the study expanded performance measures to include Return on Equity (ROE). The study controlled for firm characteristics such as leverage, firm size and assets turnover ratio. The study found that the relationships between bank's IC and financial performance indicators to be varied. The human capital efficiency and banks profitability (ROA) was positively significant except for the years 2000, 2003 and 2008. During the remaining period, it was positive but not significant. In respect to ROE, the effect human capital efficiency on bank performance was not significant in 1999 and 2006. Further, structural capital efficiency was not significantly associated to ROA and ROE in almost all of the entire period of study.

Hamdan (2018) conducted a study on 198 firms from two Gulf Cooperation Council countries: Kingdom of Saudi Arabia and Kingdom of Bahrain for the period 2014-2016 on the relationship between IC and firm performance. The study explored the use of traditional measures of performance ROA and Tobin's Q and IC was measured using VAIC model. The data was analyzed using random effects regression. The study found that IC has a significant positive impact on ROA on firms in Saudi Arabia. However, the same was not evident for firms in Bahrain. In respect to Tobin's Q, all the VAIC constituents were not statistically significant.

The ability of using IC to gain competitive advantage and eliminate risk allows the entity to be more efficient in the market. Also, it has an impact on the relationship between business partners and their involvement during the development process. Although intangible assets characterize value in an organization, managers do not have 
complete and clear information on the role that IC plays and its potential; that is, what and how many risks it generates. The competitive advantage obtained from IC cannot be easily ascertained since one requires information on IC structure and potential risks which are unique for each entity.

Studies carried out on ERM have focused on different study variables. There are studies that have looked at the determinants for ERM on performance (Pagach and Warr, 2010; Gordon et al., 2009), while others have studied characteristics of firms which adopted ERM (Hoyt and Liebenberg, 2008; Pagach and Warr, 2010). Moreover, studies have been done on the influence of ERM on firm's performance and the other aspects of the business (Hoyt and Liebenberg, 2011; McShane et al., 2011). Further, studies have been done on the roles of the key function on ERM (Beasley et al., 2005; Muralidhar, 2010) and lastly, ERM practices within ERM organizations (Ching and Colombo, 2014; Shad and Lai, 2015). This study examined the link between ERM structure practices on performance of SC in Kenya. Additionally, findings of studies on ERM structure practices and performance have inconclusive results.

Lastly, according to Togok and Suria (2014), most studies done on the effect of ERM on performance or value creation are based on experiences from developed countries like USA, United Kingdom, Germany, Canada representing $75 \%$. On the contrary, Asian and Middle East countries represent $18 \%$ and $5 \%$ respectively, while other developing countries represent $2 \%$ of the studies. Despite ERM being a concept accepted worldwide, it is always implemented and interpreted in local ways (Tekathen and Dechow, 2013). It was therefore important to join the discussion on the relationship between ERM structure practices on performance of SCs in Kenya, while moderating for intellectual capital. Hence, the study hypothesized that: -

$H_{0}$ : There is no significant moderating effect of intellectual capital on the relationship between risk structure practices and organizational performance of state corporations in Kenya.

\section{Methodology}

This study adopted positivist philosophy which usually involves collecting and converting data into numerical form so that statistical calculations can be made and conclusions drawn. The study took a quantitative approach because all the variables being considered in this research were measured, typically on instruments, so that quantitative data was analyzed using statistical procedures. This study adopted explanatory cross-sectional survey research design. The study surveyed (218) State Corporations. The study used primary data successfully collected from 197 SCs which was quantitative in nature. Primary data was obtained through structured questionnaires. The questionnaire was designed on a five point Likert -type scale ranging from (1) - strongly disagree to (5) - strongly agree. The unit of analysis was SCs, thus top-level managers were the most appropriate respondents. The target respondents were Finance Managers in SCs because they are best placed to answer the research questions.

\subsection{Measurement of Study Variables}

\subsubsection{Dependent Variable}

Organizational Performance; This study used modified and validated questions on organizational performance developed by (Ping \& Muthuveloo, 2017; Calandro \& Lane, 2006) as well as balanced score card measure of performance as presented in Table 1. Each indicator was scored and a raw score derived. The raw scores were combined to generate a composite score for organizational performance for each SC in Kenyan. The composite score of each organization was measured on a 5 point Likert scale. The composite score generated is what was used to measure organizational performance in this study.

\subsubsection{Independent Variables}

ERM structure was measured using four items; outlined objectives, culture, key risk indicators (KRIs) and key performance indicators (KPIs) as developed by Shad \& Lai (2015). The same measures were used by Laisasikorn (2014). The constructs for ERM structure were measured using a 5 point Likert scale. Joshi et al. (2015) posit that when using a Likert scale, respondents are asked to respond to each of the statement in terms of several degrees, usually five degrees of agreement or disagreement in each statement of the data collection instrument. The technique assigns a scale value to each of the five responses indicating its favorableness or unfavourableness. The scores are totaled to measure the respondent's attitude (Joshi et al., 2015).

\subsubsection{Moderating Variables}

This study measured intellectual capital using three elements: human capital, structural capital and relational capital. The dimensions were assessed using 22 items that measure the respondent's perception of IC. This was carried out using 5 point likert scale questionnaire. This study used a slightly amended version of the original survey questions developed by Bontis (1998) and modified by Cabrita and Bontis (2008). Each indicator was scored and a raw score derived. The raw scores were combined to generate a composite score for IC for each SC. This measures used are similar to those used by Cabrita and Bontis (2008); Bontis et al. (2000).

\subsubsection{Control Variables}

The study controlled for growth rate, industry differences and firm size. This study measured growth rate by using the percentage increase in the organization's revenue. This measure was also used by Beasley et al, (2005) and Waweru and Kisaka, (2013). Data on the growth rate was collected from the questionnaire. Industry differences was 
measured using dummy codes to represent each industry (Beasley et al., 2005; Waweru and Kisaka, 2013). This study measured industry differences using the dummy codes representing each industry of operation. SCs are divided into eight (8) sectors which were given dummy codes as follows; 1 - financial sector, 2 - commercial and manufacturing, 3 public universities, 4 - training and research, 5 - service corporations, 6 - tertiary education and training, 7 - regional development, and 8 - lastly, regulatory sector. Lastly, firm size has been measured using different indicators. Yegon $e t$ al., (2014) posit that firm size can be measured in terms of capital structure and asset value. Studies by Hoyt and Liebenberg (2011); Waweru and Kisaka (2013) have calculated firm size as the natural logarithm of total assets. This study adopted the same measurement of firm size. The natural logarithm of total assets was done to correct for the effect of different sizes and reduces the effect of skewness in the distribution.

Table 1: Operationalization and measurements of variables

\begin{tabular}{|c|c|c|c|}
\hline Variables & Operational Indicators & Measure & Supporting Literature \\
\hline $\begin{array}{l}\text { Organizational } \\
\text { Performance }\end{array}$ & $\begin{array}{l}\text { Composite index of organizational performance } \\
\text { (Financials, customers perspective, internal } \\
\text { business process, learning and growth) }\end{array}$ & $\begin{array}{lr}5-\quad \text { point likert } \\
\text { scale } & \text { type } \\
\text { questions } & \end{array}$ & $\begin{array}{l}\text { Ping \& } \\
\begin{array}{l}\text { (2017) } \\
\text { Calandro } \\
(2006)\end{array}\end{array}$ \\
\hline $\begin{array}{l}\text { ERM Structure } \\
\text { Practices }\end{array}$ & $\begin{array}{l}\text { Outlined objectives, culture, key risk indicators } \\
\text { (KRIs) and key performance indicators (KPIs) }\end{array}$ & $\begin{array}{lr}5-\quad \text { point likert } \\
\text { scale } \\
\text { questions }\end{array}$ & $\begin{array}{l}\text { Shad \& Lai (2015) } \\
\text { Laisasikorn }(2014)\end{array}$ \\
\hline $\begin{array}{l}\text { Intellectual } \\
\text { Capital }\end{array}$ & Human capital, structural capital, relational capital & $\begin{array}{lr}-\quad \text { point likert } \\
\text { scale } & \text { type } \\
\text { questions } & \\
\end{array}$ & $\begin{array}{l}\text { Cabrita \& Bontis (2008) } \\
\text { Bontis et al., (2000) }\end{array}$ \\
\hline Firm Size & Measured as natural logarithm of total assets & Ordinal scale & $\begin{array}{l}\text { Hoyt \& Leibenberg, } \\
(2011) \\
\text { Waweru and Kisaka, } \\
\text { 2013) }\end{array}$ \\
\hline Growth rate & Percentage increase in revenue of the organization & Ratio scale & Beasley et al. (2005) \\
\hline $\begin{array}{l}\text { Industry } \\
\text { differences }\end{array}$ & $\begin{array}{l}1=\text { financial sector, } 2=\text { commercial and } \\
\text { manufacturing, } 3=\text { public universities, } 4=\text { training } \\
\text { and research, } 5=\text { service corporations, } 6=\text { tertiary } \\
\text { education and training, } 7=\text { regional development, } \\
\text { and } 8=\text { regulatory sector }\end{array}$ & Nominal scale & $\begin{array}{l}\text { Waweru \& Kisaka, } \\
(2013)\end{array}$ \\
\hline
\end{tabular}

Source: (Researcher, 2019)

\subsection{Analytical models}

Hierarchical regression was used to determine how much the extra variable adds to the prediction of the dependent variable over and above the contribution of previously included independent variables. Baron and Kenny (1986) model was employed in the testing of the moderating role of intellectual capital. The conditional effect of $\mathrm{X}$ and $\mathrm{M}$ on $\mathrm{Y}$ is represented by $\left(\mathrm{b}_{1}+\mathrm{b}_{3} \mathrm{M}\right)$. It provides for the effect of $\mathrm{X}$ on $\mathrm{Y}$ when dependent on $\mathrm{M}$. $\mathrm{X}$ is representing $\mathrm{X}_{1}(\mathrm{ERM}$ structure) and $\mathrm{M}$ is the moderating effect of IC. This model was appropriate to test for the overall objective of the study.

Model 1 was used to test the effect of control variables on the dependent variable.

$$
\mathrm{Y}=\beta_{0}+\beta_{1} \mathrm{C}_{1}+\beta_{2} \mathrm{C}_{2}+\beta_{3} \mathrm{C}_{3}+\xi_{1}
$$

Model 2 was used to test the direct effect of $\mathrm{Xi}$ on the dependent variable.

$$
\mathrm{Y}=\beta_{0}+\beta_{1} \mathrm{C}_{1}+\beta_{2} \mathrm{C}_{2}+\beta_{3} \mathrm{C}_{3}+\beta_{4} \mathrm{X}_{1}+\xi_{1}
$$

Model 3 was used to examine the unconditional effect of $\mathrm{M}$ on the dependent variable.

$$
\mathrm{Y}=\beta_{0}+\beta_{1} \mathrm{C}_{1}+\beta_{2} \mathrm{C}_{2}+\beta_{3} \mathrm{C}_{3}+\beta_{4} \mathrm{X}_{1}+\beta_{5} \mathrm{M}_{+} \xi_{1}
$$

To test the moderating effect of intellectual capital on the relationship between structure practices and organizational performance, the following models will be used

$$
\mathrm{Y}=\beta_{0}+\beta_{1} \mathrm{C}_{1}+\beta_{2} \mathrm{C}_{2}+\beta_{3} \mathrm{C}_{3}+\beta_{4} \mathrm{X}_{1}+\beta_{5} \mathrm{M}_{+} \beta_{6} \mathrm{M} . \mathrm{X}_{1+} \xi_{1}
$$

where

$\mathrm{C}_{\mathrm{i}} \quad=$ Firm Characteristics (Control variables); where $\mathrm{C}_{1}$ (Firm size), $\mathrm{C}_{2}$ (Growth rate) and $\mathrm{C}_{3}$ (Industry differences).

$\mathrm{X}_{\mathrm{i}} \quad=$ ERM Structure Practices (independent variables)

$\mathrm{M}_{\mathrm{i}} \quad$ = Intellectual Capital (moderating variable)

$\mathrm{Y}_{\mathrm{i}} \quad=$ Organizational Performance (dependent variable)

\section{Results}

This section presents the empirical findings and interpretations of the research. 


\subsection{Descriptive Statistics}

In order to establish responses made to the research items, the mean, standard deviation, skewness and kurtosis of the study variables were determined. The mean gave indications on the average direction of the variables for each construct, while the standard deviation provided information on the level of dispersion from the mean. A low standard deviation meant that most of the responses group around the mean. In addition, kurtosis and skewness was used to establish the measures of the shape of the distribution. Kurtosis measured the "peakedness" or "flatness" of a sample distribution, while skewness measured the extent to which a distribution of values deviates from symmetry around the mean.

\subsubsection{Risk Structure Practices}

Table 2 provides the findings on risk structure practices. Risk culture was high in SCs $(\mathrm{Mean}=3.62, \mathrm{SD}=.80$ ), followed by the outlined objectives of (mean $=3.45, \mathrm{SD}=0.89)$. In terms of culture, there is an approach to determine the root cause of risk. Further, the study assessed construct validity using factor analysis. Principal components analysis (PCA) was used to assess the underlying factor structure of the given variables and also to reduce items in the model in the case of complex variables as recommended by Tabachnick and Fidell (2013). ERM structure practices were sorted and clustered into two factors which explained $65.846 \%$ of the total variance. All the items under ERM structure practices met the criteria of having a factor loading value of greater than 0.4 . They distinctively load to one of the two components extracted indicating that they significantly contributed to the construct. The Kaiser-Meyer-Olkin (KMO) had a measure of 0.932, which was above the threshold of 0.5 (Field, 2005). The Bartlett's test was significant for ERM structure practices with Chi-Square $=2443.816$, $(\mathrm{p}-\mathrm{value}<0.05)$. This implied that the sample size was adequate for the variables entered into analysis; factor analysis was appropriate for the study and there was a relationship among the variables.

The reliability of the questionnaire was therefore tested using Cronbach's alpha to assess internal consistency or homogeneity among the variables. The reliability coefficients of all the variables were above 0.70, which concurred with the suggestion made by Nunnally (1978).

Table 2: Risk Structure Practices

\begin{tabular}{|c|c|c|c|c|}
\hline $\mathrm{n}=197$ & Mean & Std. Dev & Skewness & loadings \\
\hline Outlined Objectives & 3.45 & 0.89 & -0.49 & 0.701 \\
\hline Culture & 3.62 & 0.80 & -0.55 & 0.829 \\
\hline Key Risk Indicators & 3.41 & 1.03 & -0.36 & 0.773 \\
\hline Key Performance Indicators & 3.36 & 0.88 & -0.54 & 0.903 \\
\hline ES & 3.48 & 0.78 & -0.44 & 0.911 \\
\hline \multicolumn{5}{|l|}{ Cronbach's Alpha $=.910$} \\
\hline Notes: Eigen values & 9.1 & 1.436 & & \\
\hline Percentage of Variance & 46.874 & 18.972 & & \\
\hline KMO Measure of Sampling adequacy & 0.932 & & & \\
\hline Approx. Chi-Square & \multicolumn{4}{|c|}{$2443.816(p<.05)$} \\
\hline
\end{tabular}

Source: Research Data (2019)

\subsubsection{Intellectual capital}

The study assessed intellectual capital in terms of human, structural and relational capital. The results are as presented in Table 3. Based on the findings, relational capital was high in SCs (mean $=3.78, \mathrm{SD}=0.70)$ followed by human capital (mean $=3.64, \mathrm{SD}=0.61)$. Principal component analysis with varimax rotation of factor analysis was applied because it is a reliable method (Tabachnick \& Fidell, 2013). Intellectual Capital was sorted and clustered into four factors which explained $65.826 \%$ of the total variance. The Kaiser-Meyer-Olkin (KMO) had a measure of 0.921 , which was above the threshold of 0.5 (Field, 2005). The Bartlett's test was significant for intellectual capital with ChiSquare $=2566.28$, (p-value $<0.05)$. Therefore, the KMO value of 0.921 and significance of Bartlett's statistic confirmed the appropriateness of the factor analysis for intellectual capital.

Table 3: Intellectual Capital

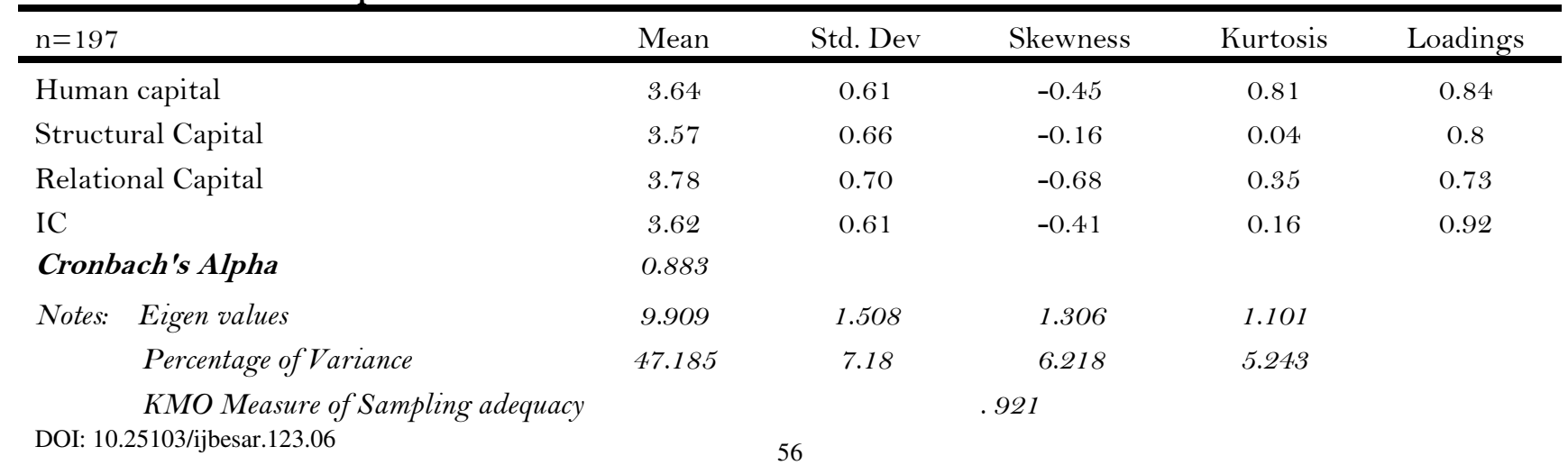


Source: Research Data (2019)

\subsubsection{Organizational Performance}

Table 4 illustrates the results on organizational performance. As evidenced in the table 4, internal business measure of performance was high in state corporation (Mean $=3.69, \mathrm{SD}=0.76$ ) closely followed by learning growth (mean $=$ $3.66, \mathrm{SD}=0.80)$ while financial perspective was least $($ mean $=3.35, \mathrm{SD}=0.94)$. All the items under organizational performance met the criteria of having a factor loading value of greater than 0.4. They distinctively loaded to one of the three components extracted indicating that that they significantly contributed to the construct. The three extracted factors explained $70.00 \%$ of the total variance. The Kaiser-Meyer-Olkin (KMO) had a measure of 0.910 , which was above the threshold of 0.5 (Field, 2005). The Bartlett's test was significant for organizational performance with Chi-Square $=2320.6$, (p-value $<0.05)$. Therefore, the KMO value of 0.910 and significance of Bartlett's statistic confirmed the appropriateness of the factor analysis for organizational performance.

Table 4: Organizational performance

\begin{tabular}{lcccc}
\hline $\mathrm{n}=197$ & Mean & Std. Dev & Skewness & Loadings \\
\hline Financial Perspective & 3.35 & 0.94 & -0.4 & 0.77 \\
Customer perspective & 3.58 & 0.81 & -0.46 & 0.859 \\
Internal Business & 3.69 & 0.76 & -0.58 & 0.773 \\
Learning Growth & 3.66 & 0.80 & -0.51 & 0.75 \\
Performance & 3.61 & 0.71 & -0.34 & 0.638 \\
Cronbach's Alpha & 0.867 & & & 1.171 \\
Notes: Eigen values & 8.466 & 1.562 & 7.319 \\
$\quad$ Percentage of Variance & 52.915 & 9.775 & & 0.91 \\
KMO Measure of Sampling adequacy & & 2320.6 & Sig. .00O \\
$\quad$ Bartlett's Test Approx. Chi-Square & & & \\
\hline
\end{tabular}

Source: Research Data (2019)

\subsection{Correlation Results}

In this study, Pearson correlation analysis was conducted to examine the relationship between variables (Wong \& Hiew, 2005). A significant and positive correlation exists between ERM structure and performance $(r=0.744, p \leq$ $0.01)$, as well as intellectual capital and performance $(\mathrm{r}=0.783, p \leq 0.01)$. For the control variables, it is only growth rate that was positively correlated with SCs performance $(r=0.142, p \leq 0.05)$. Industry differences and firm size were not correlated with the organizational performance of state corporations in Kenya as shown in Table 5.

Table 5: Correlation Results

\begin{tabular}{|c|c|c|c|c|c|c|}
\hline & PERF & ES & IC & IND & GWTH & SIZE \\
\hline PERF & 1 & & & & & \\
\hline $\mathrm{ES}$ & $.744^{* * *}$ & 1 & & & & \\
\hline IC & $.783^{* *}$ & $.671^{* *}$ & 1 & & & \\
\hline IND & 0.048 & -0.026 & 0.08 & 1 & & \\
\hline GWTH & $.142^{*}$ & 0.012 & 0.091 & -0.058 & 1 & \\
\hline SIZE & -0.075 & -0.028 & -0.076 & 0.041 & -0.054 & 1 \\
\hline
\end{tabular}

** Correlation is significant at the 0.01 level (2-tailed).

* Correlation is significant at the 0.05 level (2-tailed).

$\mathrm{ES}=\mathrm{ERM}$ Structure, IC=Intellectual Capital, PERF= Organizational Performance, IND=Industry Difference, $\mathrm{GWTH}=$ Growth Rate, SIZE $=$ Firm Size

\subsection{Testing Hypotheses}

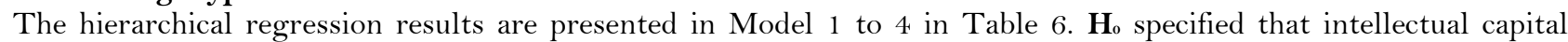
moderates the relationship between ERM structure practices and organizational performance $(\beta=.314, \rho<.05)$. Thus, the null hypothesis was rejected. This was also confirmed by $\mathrm{R}^{2} \Delta$ of .010 which indicate that intellectual capital moderates the relationship between ERM structure practices and organizational performance by $1 \%$. This implies that intellectual capital enhances the relationship between ERM structure practices and organizational performance. The implication is that, the inclusion of employees who are adequately equipped with skills to manage risks enhances the organizational performance of state corporations. 
Table 6: Moderating effect intellectual capital on risk structure practices and organizational performance

\begin{tabular}{|c|c|c|c|c|}
\hline & $\begin{array}{c}\text { Model } 1 \\
\text { B(Se) }\end{array}$ & $\begin{array}{c}\text { Model } 2 \\
\text { B(Se) }\end{array}$ & $\begin{array}{c}\text { Model } 3 \\
\text { B(Se) }\end{array}$ & $\begin{array}{c}\text { Model } 4 \\
\text { B(Se) }\end{array}$ \\
\hline (Constant) & $0.002(.071)$ & $0.001(.042)$ & $0.006(.038)$ & $0.006(.155)$ \\
\hline Zscore(IND) & $0.057(.071)$ & $0.064(.042)$ & $0.024(.038)$ & $0.027(.7240)$ \\
\hline Zscore $(\mathrm{GWTH})$ & $0.14(.071)$ & $0.093(.043)^{*}$ & $0.07(.039)$ & $0.073(1.91)$ \\
\hline Zscore(SIZE) & $(-0.07)(.071)$ & $(-0.043)(.042)$ & $(-0.021)(.038)$ & $(-0.023)(-.607)$ \\
\hline Zscore(ES) & & $0.226(.057)^{* *}$ & $0.151(.053)^{* * *}$ & $0.053(.838)$ \\
\hline Zscore $(\mathrm{EG})$ & & $0.352(.068)^{* *}$ & $0.219(.065)^{* * *}$ & $0.181(2.764)^{* *}$ \\
\hline Zscore(EP) & & $0.29(.067)^{* * *}$ & $0.197(.062)^{* *}$ & $0.156(2.479)^{*}$ \\
\hline Zscore(IC) & & & $0.38(.057)^{* *}$ & $0.229(2.874)^{* *}$ \\
\hline Zscore(ES_IC) & & & & $0.314(2.674)^{* * *}$ \\
\hline \multicolumn{5}{|l|}{ Model Summary } \\
\hline $\mathrm{R}$ & 0.166 & 0.817 & 0.855 & 0.861 \\
\hline R Square & 0.028 & 0.667 & 0.731 & 0.741 \\
\hline Adjusted $\mathrm{R}^{2}$ & 0.012 & 0.656 & 0.721 & 0.73 \\
\hline Std. Error & 0.994 & 0.587 & 0.528 & 0.520 \\
\hline \multicolumn{5}{|l|}{ Change Statistics } \\
\hline $\mathrm{R}^{2} \Delta$ & 0.028 & 0.639 & 0.064 & 0.010 \\
\hline $\mathrm{F} \Delta$ & 1.821 & 121.464 & 45.116 & 7.152 \\
\hline df1 & 3 & 3 & 1 & 1 \\
\hline $\mathrm{df} 2$ & 193.000 & 190.000 & 189.000 & 188.000 \\
\hline Sig. F $\Delta$ & 0.145 & 0.000 & 0.000 & 0.008 \\
\hline
\end{tabular}

$\mathrm{ES}=\mathrm{ERM}$ Structure, IC=Intellectual Capital, PERF= Organizational Performance, IND=Industry Difference, GWTH= Growth Rate, SIZE $=$ Firm Size, and ES-IC = (ERM Structure* Intellectual Capital $)$

Source: Research Data (2019)

Previous scholars reiterated that the most optimal way to know the nature of the interaction effect of the moderator is to plot them in a graph (Jose, 2008). Mod Graphs help to simplify the interpretation of the complex nature of interactions in the model. Thus, the results in Table 6 can be plotted on Mod Graphs to provide a logical interpretation of interaction effects of intellectual capital in the relationship between ERM structure practices and organizational performance of SCs. The Mod Graphs are presented in Figure 1. It has been demonstrated in Figure 1 that higher levels of intellectual capital within SCs result to a steeper slope between ERM structure practices and organizational performance, hence, the null hypothesis $\mathrm{H}_{\mathrm{o}}$ was not supported. This implied that intellectual capital positively and significantly moderates the relationship between ERM structure practices and organizational performance.

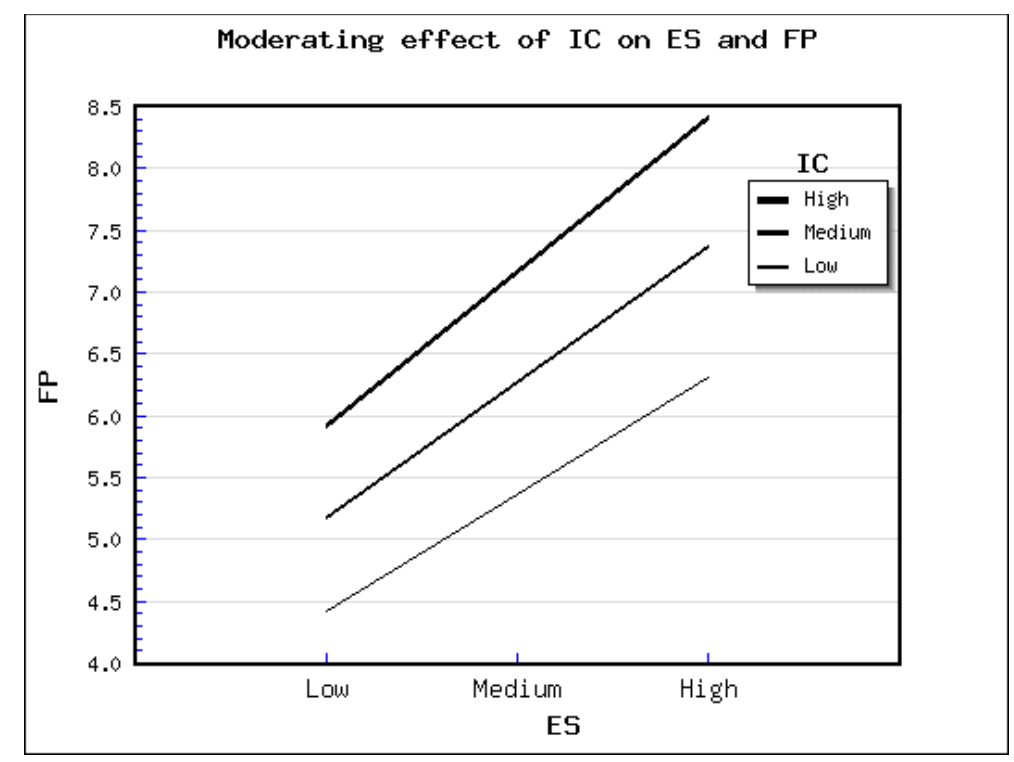




\section{Figure 4.1 Moderated effect of intellectual capital on the relationship between ERM structure and organizational performance}

The findings of this study are in agreement with those of Olayinka et al. (2017); Shad and Lai (2015) which indicate that ERM structure practices have positive and significant effect on financial performance. On the other hand, the findings of this study contradicts those of Laisasikorn (2014); Quon et al. (2012) which found no significant relationship between ERM structure practices and performance. Similarly, Acharyya, (2009) concluded that insurers' stock market performance is dependent on the characteristics of the industry rather ERM structure practices.

\section{Conclusion and Recommendations}

The results indicate that intellectual capital positively and significantly moderates the relationship between ERM structure practices and organizational performance. This may be attributed to employees' competences that match their job requirements. Besides, the systems within SCs are efficient and information in the organization's database can easily be accessed by the authorized persons. Further, procedures are in place that support innovation and that systems allow information sharing. Nonetheless, it is unclear if there is high level of bureaucracy in operations. Furthermore, customers are generally satisfied hence there are many loyal customers. Moreover, SCs have capitalized on customers' needs and understanding their target market. Besides, information about the organizations' products and services is usually disseminated to the customer. Also, the organization has scheduled activities for meeting with its customers. Finally, customers' feedback is highly valued. This is in agreement with Welbourne (2008) who states that relational capital as an intangible asset that is based on developing, maintaining and nurturing high- quality relationships with any organization, individuals or group that influences or impacts the business.

\subsection{Managerial implication}

Risk structure practices are essential for reduction of risk exposure and operational cost thus facilitating improvement in SCs overall performance. Also, it is important for SCs to define key areas of authority and the degree to which individuals and teams are authorized to act while addressing issues, solving problems and taking advantage of opportunities. Moreover, firms need to capitalize on personnel who act as risk identifying champions and ensure that employees are trained on ERM. Further, SCs need to adopt an approach that is effective in determining the root cause of risk so that each risk is identified right from the onset and the best course of action determined.

\subsection{Theoretical implication}

The study contributes to literature on organizational performance by providing empirical evidence on the moderating effect of intellectual capital on the relationship between ERM practices and organizational performance. Also, the study contributes to dynamic capabilities theory by examining the implication of intellectual capital on ERM practices which is considered as a strategy adopted by organizations to enhance performance. In addition, the study supports the theory of Enterprise Risk Management (ERM) that emphasizes on holistic, company-wide approach in managing risks (Hoyt and Liebenberg, 2011).

This study expands knowledge on the moderating effect of intellectual capital on the relationship between enterprise risk management practices and organizational performance of Kenyan state corporations. Though this study has fulfilled its aim and objectives, there are limited studies that have focused on moderating variables for ERM and organizational performance. Therefore, exploratory and empirical studies should be conducted to determine moderating variables for ERM and organizational performance. In addition, the risk profile and dynamics of intellectual capital are unique to each organizations and may be affected by regulatory frameworks across different sectors, countries and regions. For this reason, further empirical investigations in different regions and countries are needed.

\section{References}

Acharyya, M. (2009). The Influence of Enterprise Risk Management on Insurers's Stock Market Performance- An Event Analysis. International Journal of Business and Management Invention, 44(3), 121-136.

Adner, R. \& Helfat, C.E. (2003). Corporate Effects and Dynamic Managerial Capabilities. Strategic Management Journal, 24 (10), 1011-1025.

Barney, J. B. (2002). Gaining and Sustaining Competitive Advantage (Second). Upper Saddle River: Pearson Education Inc.

Baron, R.M., \& Kenny, D. A. (1986). The Moderator-Mediator Variable Distinction in Social Psychological Research: Conceptual, Strategic and Statistical Considerations. Journal of Personality and Social Psychology, 51, 1173-1 182.

Beasley, M.s, Clune, R., and Hermson, D. (2005). Enterprise Risk Management: An Empirical Analysis of Factors Associated with the Extend of Implementation. Journal of Accounting and Public Policy, 24(6), 521-531.

Bontis, N. (1998). Intellectual Capital: An Exploratory Study that Develops Measures and Models. Management Decision, 36 (2), $63-$ 76.

Bontis, N., Keow, W. \& Richardson, S. (2000). Intellectual Capital and Business Performance in Malaysian Industries. Journal of Intellectual Capital, 1 (1), 85-100.

Bontis, N. \& Mention, A. (2013). Intellectual Capital and Performance Within the Banking Sector of Luxembourg and Belgium. Journal of Intellectual Capital, 14 (2), 286-309.

DOI: 10.25103/ijbesar.123.06 
Bozkus, S. (2014). ERM at Work: The Recommendations for Best Practice. Journal of Business and Management, 4360(1), 89-100.

Cabrita, M. \& Bontis, N. (2008). Intellectual Capital and Business Performance in the Portuguese Banking Industry. International Journal of Technology Management, 43(13), $212-237$.

Calandro, J., \& Lane, S. (2006). An introduction to the Enterprise Risk Scorecard. Measuring Business Excellence, 10(3), 31-40. https://doi.org/10.1108/13683040610685775

Ching, H. Y., and Colombo, T. (2014). Enterprise Risk Management Good Practices and Proposal of Conceptual Framework. Journal of Management Research, 6(3). https://doi.org/10.5296/jmr.v6i3.5404

Field, A. (2005). Reliability Analysis. Discovering Statistics Using SPSS. 2nd Edition, Sage, London

Florio, C., \& Giulia, L. (2016). Enterprise risk management and firm performance: The Italian Case. The British Accounting Review, 49(1), 56-74.

Gordon, L. A., Loeb, M. P., \& Tseng, C. (2009). J . Account . Public Policy Enterprise risk management and firm performance : A contingency perspective. Journal of Accounting and Public Policy, $28(4)$, 301-327. https://doi.org/10.1016/j.jaccpubpol.2009.06.006

Grant, R. M. (1991). The Resource-Based Theory of Competitive Advantage. California Management Review, 33, $114-135$. http://dx.doi.org/10.2307/41166664

Hamdan, A., (2018) Intellectual Capital and Firm Performance: Differentiating between Accounting Based and Market-Based Performance. International Journal of Islamic and Middle Eastern Finance and Management, 11(1), $139-151$.

Helfat, C. E., \& Peteraf, M. A. (2003). The Dynamic Resource-Based View: Capability Lifecycles. Strategic Management Journal, 24: 997-1010.

Hofer, C. (2003). A New Measure for Assessing Organizational Performance (Third). New York: Jai Press.

Hoyt, R.E., \& Liebenberg, A. (2011). The Value of Enterprise Risk Management. Journal of Risk and Insurance, 78(4), 792-822.

Jose, P. E. (2008). ModGraph-I: A Programme to Compute Cell Means for the Graphical Display of Moderation Analyses: The internet version, Version 2.0. Retrieved July 22, 2019, from http://www.victoria.ac.nz/psyc/staff/paul-josefiles/modgraph/modgraph.php.

Joshi, A., Kale, S., Chandel, S. \& Pal, D. K. (2015). Likert Scale: Explored and Explained. British Journal of Applied Science E̊ Technology, 7(4): 396-403, 2015.

Kenya National Bureau of Statitics. (2015). Economic Survey. Nairobi.

Laisasikorn, K. (2014). A Study of the Relationship Between a Successful Enterprise Risk Management System, a Performance Measurement System and the Financial Performance of Thai Listed Companies. International Journal of Business and Management Invention, 16(2), 81-92.

Marr, B., Schiuma, G. and Neely, A. (2004). Intellectual Capital-Defining Key Performance Indicators for Organizational Knowledge Assets. Business Process Management Journal, 10 (5), 551-569, available at: http: //dx.doi.org/10.1108/14637150410559225

McShane, M.K., Nair, A., \& Rustambekov, E. (2011). Does Enterprise Risk Management Increase Firms Value? Journal of Accounting, Auditing E् Finance, 26(4), 641-658.

Mondal, A. \& Ghosh, S. K. (2012). Intellectual Capital and Financial Performance of Indian banks. Journal of Intellectual Capital, 13 (4), 515-530.

Muralidhar, K. (2010). Enterprise Risk Management in the Middle East Oil Industry; An Empirical Investigation Across GCC Countries. International Journal of Energy Sector Management, 4(1), 59-86.

Nunnally, J. C. (1978). Psychometric Theory (Second). New York: McGraw-Hill.

Olayinka, E., Emoarehi, E., Jonah, A., \& Ame, J. (2017). Enterprise Risk Management and Financial Performance: Evidence from Emerging Market. International Journal of Management, Accounting and Economics, 4(9), 937-952.

Ongeti, W. (2014). Organizational Resources, Corporate Governance Structures and Performance of Kenyan State Corporations . International Accounting Journal, 65(8), 346-356.

Pagach, D., \& Warr, R. (2010). The Effects of Enterprise Risk Management on Firm Performance. International Journal of Social Economics, 4(11), 45-98.

Ping, T. A., \& Muthuveloo, R. (2017). The Impact of Enterprise Risk Management on Firm Performance: Evidence from Malaysia. Asian International Journal, 1 1(22), 149-159. https://doi.org/10.5539/ass.v11n22p149

Quon, T. K., Zeghal, D., \& Maingot, M. (2012). Enterprise Risk Management and Firm Performance. IOSR Journal of Business and Management, 62(2), 263-267. https://doi.org/10.1016/j.sbspro.2012.09.042

Republic of Kenya. (2013). Report of the Presidential Task Force on Parastatal Reforms. Nairobi.

Shad, M. K., \& Lai, F. (2015). A Conceptual Framework for Enterprise Risk Management Performance Measure through Economic Value Added. Global Business and Management Research; An International Journal, 7(2), 1-11.

Sofian S., Saeidi P., \& Rasid S. (2014). A Proposed Model of the Relationship between Enterprise Risk Management and Firm Performance. International Journal of Information Processing and Management. 5(2), 70-80.

Stewart, T.A. (1997), Intellectual Capital: The New Wealth of Organizations, Bantam Doubleday Dell Publishing Group, New York, NY.

Tabachnick, B. G., \& Fidell, L. S. (2013). Using Multivariate Statistics (6th ed.). Boston, MA: Pearson.

Tekathen, M., \& Dechow, N. (2013). Enterprise Risk Management and Continuous Re-Alignment in the Pursuit of Accountability: A German Case. Management Accounting Research Journal, 24(2), 100-121.

Ting, I. W. K. \& Lean, H. H. (2009). Intellectual Capital Performance of Financial Institutions in Malaysia. Journal of Intellectual Capital, $10(4), 588-599$.

Togok, S.H., \& Suria, Z. (2014). Review of Enterprise Risk Management. International Journal of Business Research, 9(4), $24-36$.

Waweru, N., \& Kisaka, E. (2013). The Effect of Enterprise Risk Management Implementation on the Value of Companies Listed on the Nairobi Stock Exchange. Journal of Applied Finance E Banking, 3(3), 81-105. https://doi.org/10.2 139/ssrn.2326195

Welbourne, T.M. (2008). Relational Capital: Strategic Advantage for Small and Medium-Sized Enterprises (SMEs) through Negotiation and Collaboration. Journal of Business and Economics, Vol. 18 No. 5, pp. 438-92.

Wohlgemuth, V. \& Bogodistov, Y. (2017). Enterprise Risk Management: A Capability-Based Perspective. The Journal of Risk Finance, 18 (3), 234-251. 
Wong, C. \& Hiew, P. L. (2005). Diffusion of Mobile Entertainment in Malaysia: Drivers and Barriers. 5. 263-266. DOI: $10.1145 / 1089551.1089661$

Wood, A. \& Lewis, A. (2018). Risk Culture Development and its Impact: The Case of the Caribbean Development Bank. International Journal of Business and Economic Development, 6 (1), 18-37.

Yegon, C. K., Mouni, J. G., \& Wanjau, K. (2014). Effects of Firm Size on Enterprise Risk Management of Listed Firms in Kenya. IOSR Journal of Business and Management, 16(5), 86-95.

This is an Open Access article distributed under the terms of the Creative Commons Attribution Licence

(9) 